\title{
Perencanaan Gedung Park and Ride di Stasiun Bojong Gede Kecamatan Bojong Gede Kabupaten Bogor Jawa Barat
}

\author{
Salman Al Farisi dan Wahju Herijanto \\ Departemen Teknik Sipil, Institut Teknologi Sepuluh Nopember (ITS) \\ e-mail: herijanto@ce.its.ac.id
}

\begin{abstract}
Abstrak - Kabupaten Bogor adalah kabupaten yang merupakan dari megapolitan Jabodetabek dan menjadi kabupaten dengan jumlah 5,13 juta penduduk. Kebutuhan akan moda transportasi kini sudah menjadi hal yang sangat penting bagi penduduk suatu kota. Karena transportasi merupakan sarana yang sangat penting dalam memperlancar roda perekonomian suatu wilayah. Untuk itu dibutuhkan sebuah solusi untuk mengurangi kemacetan dengan cara memaksimalkan manfaat dari transportasi umum yang sudah ada seperti kereta listrik atau Commuter Line. Fasilitas penunjang kereta listrik di stasiun Bojong Gede sangat minim apalagi dalam hal kantung parkir menyebabkan banyak kantung parkir liar yang dimiliki oleh warga sekitar dan mengakibatkan lahan untuk pedestrian diapakai juga untuk parkir sehingga orang yang berjalan kaki harus mengambil lajur untuk kendaraan bermotor. Maka dari itu salah satu solusi yang dapat dilakukan adalah pembangunan Gedung Park and Ride sebagai fasilitas penunjang transportasi pada Stasiun Bojong Gede. Dari hasil pengolahan data didapatkan jumlah demand calon pengguna fasilitas park and ride untuk sepeda motor sebanyak 3.454 kendaraan, sedangkan untuk mobil sebanyak 192 kendaraan dengan umur rencana hingga 2024. Dari jumlah demand tersebut direncanakan gedung park and ride yang dapat menampung 3.479 sepeda motor dan 193 mobil dengan jumlah 8 lantai parkir dan 1 lantai untuk akses menuju peron.
\end{abstract}

Kata Kunci-Commuter Line, Kabupaten Bogor, Park and Ride, Stasiun Bojong Gede.

\section{PENDAHULUAN}

K ABUPATEN Bogor adalah kabupaten yang merupakan bagian dari megapolitan Jabodetabek dan telah menjadi kabupaten dengan jumlah penduduk mencapai 5,13 juta jiwa [1]. Saat ini Kabupaten Bogor berkembang menjadi tempat tinggal kaum urban dan sentra industri. Kabupaten Bogor berkembang sangat cepat baik dari segi infrastruktur kota maupun segi perekonomian. Seiring dengan berkembangnya perekonomian warga setempat, jumlah pemilik dan pengguna kendaraan pribadi di Kabupaten Bogor pun meningkat pesat, yang menyebabkan terjadinya kemacetan karena tidak disertai dengan peningkatan fasilitas penunjang transportasi. Karena minimnya fasilitas penunjang transportasi di Stasiun Bojong Gede terutama dalam lahan parkir maka munculah kantung parkir liar yang dimiliki oleh warga sekitar mengakibatkan kemacetan di sekitar stasiun karena kantung parkir warga memakai lahan pejalan kaki sehingga menyebabkan pejalan kaki harus memakai lajur untuk kendaraan bermotor.

Kegiatan ekonomi di daerah Jabodetabek terpusat di daerah Jakarta. Setiap hari ada sekitar 9,96 juta perjalanan per hari menuju Jakarta. Hal ini mengakibatkan padatnya jalan arah luar Kabupaten Bogor yang mengakibatkan kemacetan panjang yang berdampak pada roda perkonomian warga.

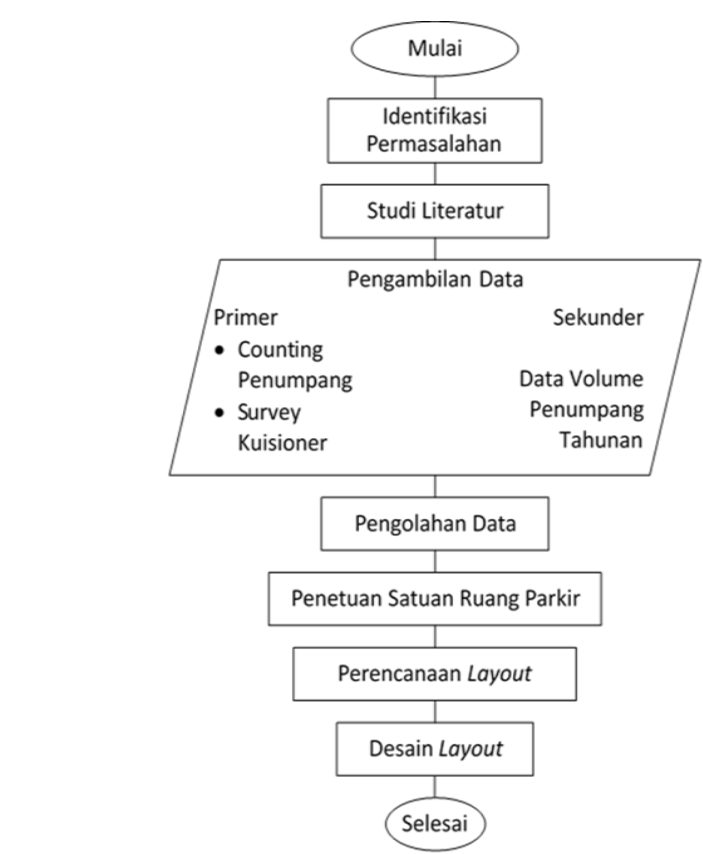

Gambar 1. Diagram alir perencanaan Gedung Park and Ride.

Oleh sebab itu, dibutuhkan sebuah solusi untuk mengurangi kemacetan dengan cara memaksimalkan manfaat dari transportasi umum seperti Commuter Line Jabodetabek, dan angkutan kota atau bus yang nantinya dapat menghubungkan setiap tempat di daerah Jabodetabek. Salah satu solusi yang bisa dilakukan adalah dengan memaksimalkan fasilitas penunjang di dalam stasiun agar dapat menambah ketertarikan pengguna transportasi umum, seperti ketersediaan lahan parkir kendaraan pribadi bagi calon pengguna yang luas dan nyaman. Dengan adanya lahan parkir yang nyaman, murah, dan aman seharusnya dapat menambah kepercayaan para pengguna transportasi umum dan pengguna mobil probadi di lingkungan Kabupaten Bogor agar tertarik menggunakan transportasi umum.

Gedung Park and Ride diharapkan dapat menyediakan tempat yang cukup luas dan baik untuk menampung kendaraan pribadi dan mengurangi kendaraan yang menuju arah luar kota sehingga dapat memaksimalkan kegiatan perekonomian dengan harapan masyarakat akan berpindah menggunakan transportasi umum ketika melakukan aktivitas di luar kota [2]. Solusi ini dapat berdampak banyak bagi Kabupaten Bogor karena dapat mengurangi kemacetan yang terjadi di jalan alar luar kota dan di sekitar stasiun sehingga dapat juga mengefektifkan kegiatan perekonomian yang selama ini menjadi kurang efektif karena kemacetan di beberapa titik arah luar Kabupaten Bogor dan sekitar Stasiun Bojong Gede. 


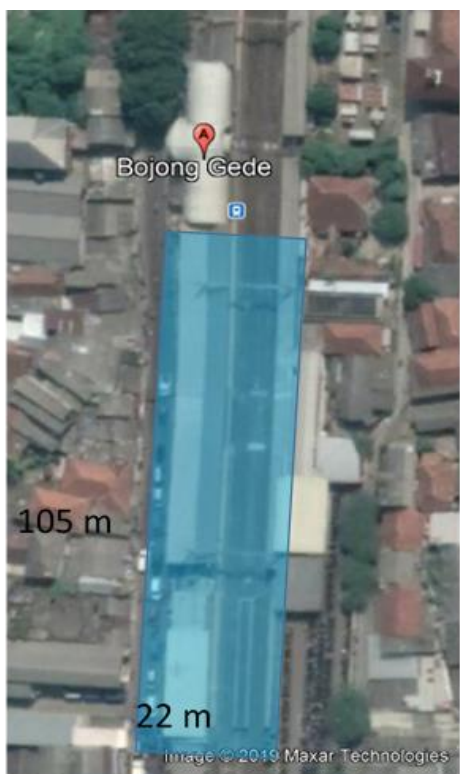

Gambar 2. Gambar sketsa laha Gedung Park and Ride di Stasiun Bojong Gede.

\section{A. Permasalahan Utama}

Berapa demand Park and Ride pada tahun 2024 (umur rencana 5 tahun) dan bagaimana layout-nya?

\section{B. Detail Permasalahan}

1. Berapa besar presentase orang yang menggunakan park and ride di Stasiun Bojong Gede?

2. Berapa demand/permintaan park and ride pada periode lima (2024) tahun mendatang?

3. Bagaimana bentuk desain layout dari Gedung Park and Ride?

\section{METODOLOGI}

\section{A. Diagram Alir}

Diagram alir dalam perencanaan Gedung Park and Ride. Berikut ini adalah diagram alir seperti ditunjukkan pada Gambar 1.

\section{ANALISIS DAN PERHITUNGAN}

\section{A. Data Guna Lahan}

Rencana lokasi park and ride terletak di Stasiun Bojong gede yang berada di Kecamatan Bojong Gede Kabupaten Bogor. Lahan yang akan dijadikan tempat parkir adalah berada diatas Stasiun Bojong Gede. Berikut ini adalah gambaran sketsa dari lokasi perencanaan Gedung Park and Ride ditunjukkan pada Gambar 2.

Luas Lahan

Luas lahan yang terletak di atas stasiun eksisting Stasiun Bojong Gede adalah $22 \mathrm{~m}$ x $105 \mathrm{~m}$ atau sebesar $2.310 \mathrm{~m}^{2}$.

\section{B. Jumlah Penumpang di Stasiun Bojong Gede}

Pertumbuhan jumlah penumpang di Stasiun Bojong Gede mengalami peningkatan di tiap tahunnya sehingga menyebabkan fasilitas penunjang transportasi umumnya pun juga harus diperbaiki. Berikut ini adalah data jumlah penumpang setiap tahunnya di Stasiun bojong Gede seperti yang ditunjukkan pada Tabel 1.

\section{Jumlah Penumpang Counting}

Perencanaan Park and Ride di Stasiun Bojong Gede ini bertujuan agar masyaratak dapat memerkirkan kendaraannya di tempat parkir selayaknya hingga dapat lebih dekat dengan stasiun dan menggunakan angkutan massal Commuter Line untuk berkegiatan selanjutnya.

Untuk itu dibutuhkan data jumlah penumpang yang didapatkan dari counting. Data counting diambil dari jumlah penumpang yang masuk di Stasiun Bojong Gede. Counting dilakukan pada pukul 06.00-08.00 WIB, rentang waktu tersebut dipilih karena pada jam tersebut adalah waktu rush hour dimana orang berangkat kerja. Berikut ini adalah hasil counting jumlah penumpang ditunjukkan pada Tabel 2.

\section{Penentuan Jumlah Sampel}

Jumlah sampel ditentukan terlebih dahulu sebelum melakukan survei kuisioner. Dalah perencanaan ini, responden merupakan penumpang commuter line yang naik dari Stasiun Bojong Gede. Untuk mendapatkan jumlah responden yang akan dapat mewakili jumlah populasi yang ada. Maka dari itu dibutuhkan jumlah sampel yang tepat.

Analisis menggunakan rumus Slovin unutuk menghitung presentase kesalahan dari survei kuisioner ini. Oleh karena itu dibutuhkan jumlah penumpang dari hasil counting tadi. Berikut ini adalah rumus Slovin.

$$
n=\frac{N}{N \cdot d^{2}+1}
$$

Dimana,

$\mathrm{N}$ = Jumlah Penumpang hasil Counting

$\mathrm{n} \quad=$ Jumlah Sampel

$\mathrm{d} \quad=$ Galat pendugaan (dipakai 10\%)

dengan volume penumpang hasil counting sebanyak 3.901 orang, sehingga

$$
\begin{gathered}
n=\frac{3901}{3901 \times 0,1^{2}+1} \\
n=97,5
\end{gathered}
$$

Jadi, jumlah sampel yang digunakan adalah sebanuyak 98 responden.

\section{E. Hasil Survey Kuisioner}

$$
\begin{aligned}
\text { a. Jenis Kelamin } & \\
\text { Laki-laki } & =51 \% \\
\text { Perempuan } & =49 \% \\
\text { b. Usia } & \\
<20 \text { Tahun } & =42 \% \\
\text { 20-40 Tahun } & =50 \% \\
>40 \text { Tahun } & =8 \% \\
\text { c. Maksud Perjalanan } & \\
\text { Bekerja } & =45 \% \\
\text { Sekolah } & =12 \% \\
\text { Rekreasi } & =5 \% \\
\text { Lainnya } & =38 \% \\
\text { d. Durasi Perjalanan } & \text { Parkir } \\
<5 \text { Jam } & =16 \% \\
\text { 5-8 Jam } & =52 \% \\
>8 \text { Jam } & =32 \%
\end{aligned}
$$

$\begin{array}{ll}\text { Bekerja } & =45 \% \\ \text { Sekolah } & =12 \% \\ \text { Rekreasi } & =5 \% \\ \text { Lainnya } & =38 \%\end{array}$

e. Kendaraan yang digunakan

$$
\text { Mobil }=4 \%
$$


Tabel 1.

Data Jumlah Penumpang

\begin{tabular}{cc}
\multicolumn{2}{c}{ Data Jumlah Penumpang } \\
\hline Tahun & Jumlah Penumpang \\
\hline 2015 & 10.792 .330 \\
2016 & 11.459 .118 \\
2017 & 11.587 .163 \\
2018 & 11.627 .566 \\
\hline \hline
\end{tabular}

Tabel 2.

Hasil counting

\begin{tabular}{ccc}
\hline \multicolumn{3}{c}{ Hasil counting } \\
\cline { 2 - 3 } Waktu & \multicolumn{3}{c}{ Pengguna } \\
\cline { 2 - 3 } & Pintu 1 & Pintu 2 \\
\hline $06.00-06.15$ & 186 & 285 \\
$06.15-06.30$ & 191 & 301 \\
$06.30-06.45$ & 194 & 293 \\
$06.45-07.00$ & 196 & 325 \\
$07.00-07.15$ & 221 & 316 \\
$07.15-07.30$ & 203 & 290 \\
$07.30-07.45$ & 175 & 288 \\
$07.45-08.00$ & 173 & 264 \\
Sub Total & 1.539 & 2.362 \\
Total & & 3.901 \\
\hline
\end{tabular}

$\begin{array}{ll}\text { Motor } & =74 \% \\ \text { Angkutan } & =18 \% \\ \text { Lainnya } & =4 \%\end{array}$

f. Pengeluaran BBM Motor (/bulan)

$<200 \mathrm{ribu}=79 \%$

$200-400$ ribu $=15 \%$

$>400$ ribu $=6 \%$

g. Pengluaran BBM Mobil (/bulan)

$$
\begin{aligned}
& <600 \text { ribu }=79 \% \\
& 600-900 \text { ribu }=17 \% \\
& >900 \text { ribu }=4 \%
\end{aligned}
$$

h. Apabila dibangun Park and Ride apakah ingin menggunakannya

Ya, ingin menggunakan $\quad=98 \%$

Tidak ingin menggunakan $=3 \%$

\section{F. Tarif Parkir yang Diinginkan}

Dari hasil survey kuisioner yang sudah dilakukan, tarif parkir yang diinginkan untuk Sepeda Motor adalah Rp 5.000 untuk sekali masuk dan untuk Mobil adalah Rp 10.000 untuk sekali masuk

\section{G. Pertumbuhan Jumlah Penumpang}

Pertumbuhan penumpang dalam perencanaan ini direncanakan selama 5 tahun kedepan. Metode yang digunakan adalah metode regresi linear. Berikut ini adalah grafik dari data yang sudah didapatkan dari Commuter Line Stasiun Bojong Gede seperti pada Gambar 3.

Dari Gambar 3 didapatkan persamaan regresi linear seperti berikut

$$
Y=263.375,3 x-519.729 .748,20
$$

Dari rumus yang sudah didapatkan, dilakukan perhitungan dengan variable $x$ adalah Tahun yang direncanakan dan $y$ adalah jumlah penumpang, Tabel 3 hasil dari perhitungan forecasting regresi linear

\section{H. Demand Park and Ride}

Hasil kuisioner didapatkan presentase pengguna sepeda motor yaitu $74 \%$ dan untuk mobil sebesar $4 \%$ dengan jumlah hasl counting sebanyak 3.901 penumpang, maka

$$
\begin{aligned}
\text { Sepeda Motor } & =74 \% \times 3.901 \\
& =2.887 \text { Sepeda Motor } \\
\text { Mobil Pribadi } & =4 \% \times 3.901 \\
& =157 \text { Mobil }
\end{aligned}
$$

Tabel 3.

Hasil forecasting jumlah penumpang

\begin{tabular}{cc} 
Tahun & Jumlah Penumpang \\
\hline $2015^{*}$ & 10.792 .330 \\
$2016^{*}$ & 11.459 .118 \\
$2017^{*}$ & 11.587 .163 \\
$2018^{*}$ & 11.627 .566 \\
$2019^{* *}$ & 12.024 .983 \\
$2020^{* *}$ & 12.288 .358 \\
$2021^{* *}$ & 12.551 .733 \\
$2022^{* *}$ & 12.815 .108 \\
$2023^{* *}$ & 13.078 .484 \\
$2024^{* *}$ & 13.341 .859
\end{tabular}

Ket.

* Jumlah penumpang eksisting data dari Stasiun

** Jumlah penumpang hasil forecasting

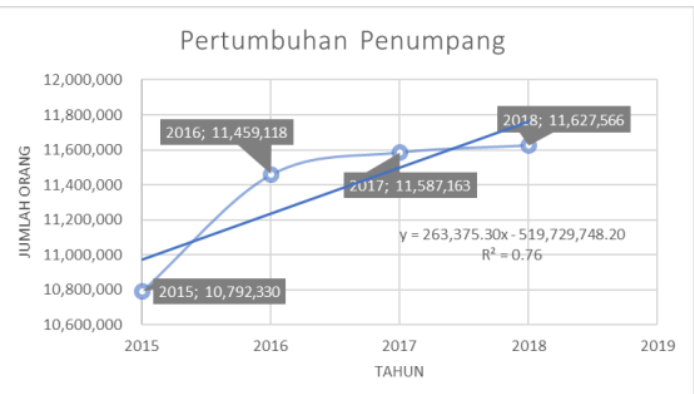

Gambar 3. Grafik Regresi Perumbuhan Penumpang.

Dari hasil kuisioner juga didapatkan presentese keinginan masing-masing pengguna sepeda motor maupun mobil yang inin menggunakan fasilias park and ride yaitu untuk sepeda motor sebanyak $98 \%$ sedangkan untuk mobil sebesar $100 \%$, maka

Sepeda Motor $\quad=98 \%$ x 2.887 Sepeda Motor

$\begin{aligned} & =2.830 \text { Kendaraan } \\ \text { Maksimum } & =2.830+(2.830 \times 10 \%)\end{aligned}$

Mobil $\quad 3.113$ Sepeda Moto

$\begin{aligned} & =157 \text { Mobil } \\ \text { Maksimum } & =157+(157 \times 10 \%)\end{aligned}$

$$
=173 \text { Mobil }
$$

Dari hasil perhitungan diatas dapat disimpulkan bahwa demand pengguna park and ride untuk sepeda motor sebanyak 3.113 kendaraan dan untuk mobil sebanyak 173 kendaraan.

\section{Forecasting Demand untuk Umur 5 Tahun Rencana}

Dari hasil perhitungan poin I dilakukan forecasting untuk umur rencana 5 tahun 2024) dengan data jumlah penumpang yang diketahui untuk Tahun 2019 sebanyak 12.024.983 penumpang sedangkan untuk tahun 2024 sebanyak 13.341.859 penumpang, maka

Penumpang $2024=13.341 .859$ orang

Penumpang $2019=12.027 .983$ orang

Demand motor =

$$
\begin{gathered}
\text { demand } 2019 \times \frac{\text { Penumpang } 2024}{\text { penumpang } 2019} \\
3.113 \times \frac{13.341 .859}{12.024 .983}
\end{gathered}
$$

$=3.454$ Motor

Demand mobil

$$
\begin{array}{r}
\text { demand } 2019 \times \frac{\text { Penumpang } 2024}{\text { penumpang } 2019} \\
173 \times \frac{13.341 .859}{12.024 .983}
\end{array}
$$




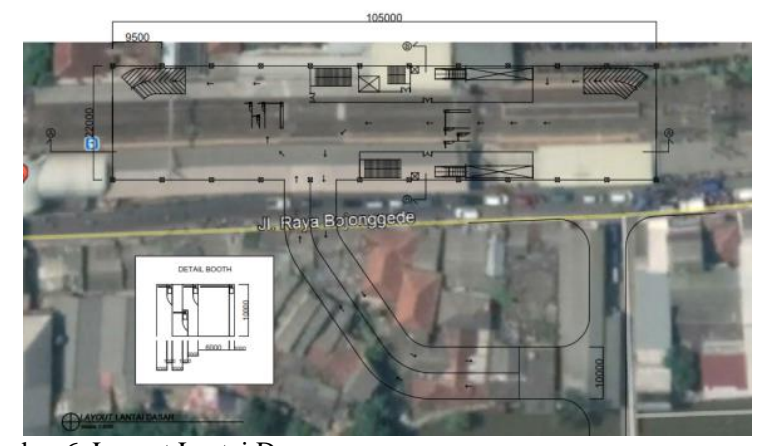

Gambar 6. Layout Lantai Dasar.
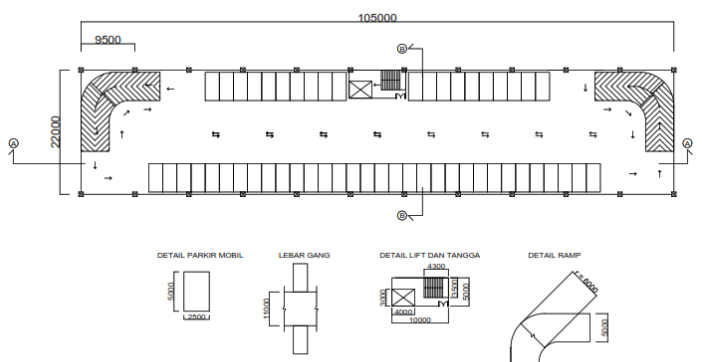

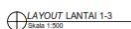

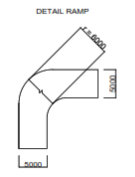

Gambar 7. Layout Lantai 1-3.

\section{= 192 Mobil}

\section{J. Perhitungan Booth Parkir}

Booth Sepeda Motor

Lama Pelayanan $\quad=4$ detik

Tingkat Kedatangan =

$$
\begin{gathered}
\lambda=\frac{\text { jumlah sepeda motor }}{2} \\
\lambda=\frac{3.454}{2 \mathrm{jam}} \\
\lambda=1.727 \text { kendaraan } / \mathrm{jam}
\end{gathered}
$$

Tingkat pelayanan $=$

$$
\begin{aligned}
\mu & =\frac{3.600 \text { detik }}{4 \text { detik }} \\
\mu & =900 \text { kendaraan }
\end{aligned}
$$

Direncanakan menggunakan 1 booth, maka:

Intensitas

$$
\begin{aligned}
& = \\
& p=\frac{\lambda}{\mu} \\
& p=\frac{1.727}{900} \\
& p=1,91
\end{aligned}
$$

Karena $p>1$ maka menunjukkan pelayanan dengan menggunakan 1 booth belum memenuhi kriteria karena tingkat kedatangan lebih besar dibanding tingkat pelayanan. Maka direncanakan menggunakan 3 booth.

Dengan perhitungan yang sama didapatkan tingkat kedatangan sebesar 576 kendaraan/jam/booth, tingkat pelayanan sebesar 900 kendaraan dan dengan intesitas sebesar 0,64 maka panjang antriannya sebagai berikut:

Panjang antrian

$$
\begin{gathered}
= \\
q=\frac{p}{1-p} \\
q=\frac{0,64}{1-0,64} \\
q=1,78 \approx 2 \text { kendaraan }
\end{gathered}
$$

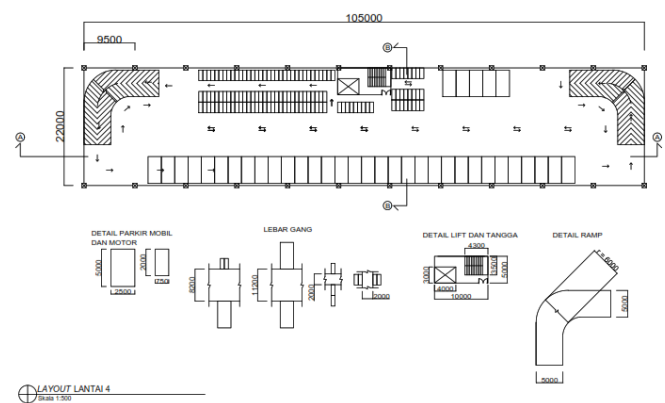

Gambar 4. Layout Lantai 4.

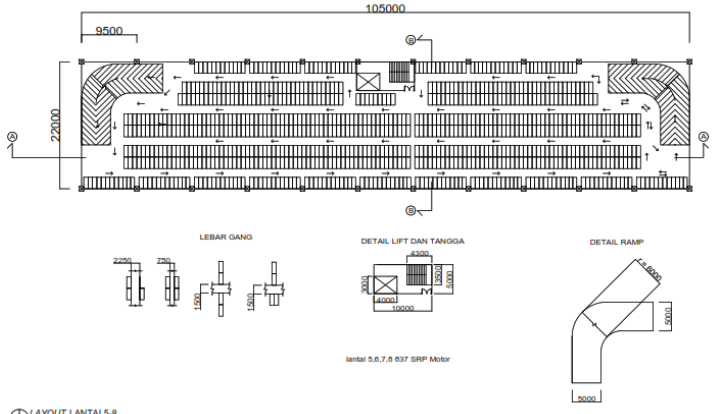

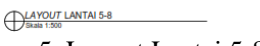

Maka booth parkir untuk sepeda motor direncanakan sebanyak 3 booth parkir

Booth Mobil Pribadi

Lama Pelayanan $\quad=4$ detik

Tingkat Kedatangan =

$$
\begin{gathered}
\lambda=\frac{\text { jumlah mobil pribadi }}{2 \text { jam }} \\
\lambda=\frac{192}{2 \text { jam }} \\
\lambda=96 \text { kendaraan } / \mathrm{jam}
\end{gathered}
$$

Tingkat pelayanan

$$
\begin{aligned}
\mu & =\frac{3.600 \text { detik }}{4 \text { detik }} \\
\mu & =900 \text { kendaraan }
\end{aligned}
$$

Direncanakan menggunakan 1 booth, maka:

Intensitas

$$
\begin{aligned}
& \begin{array}{l}
= \\
p=\frac{\lambda}{\mu}
\end{array} \\
& p=\frac{96}{900} \\
& p=0,11
\end{aligned}
$$

Karena $p \leq 1$ maka tingkat pelayanan dengan menggunakan 1 booth sduah memenuhi kriteria karena tingkat kedatangan lebih kecil dibanding tingkat pelayanan. Maka panjang antrian dengan menggunakan 1 booth seperti berikut:

$$
\begin{aligned}
& q=\frac{p}{1-p} \\
& q=\frac{0,11}{1-0,11}
\end{aligned}
$$

$q=0,13 \approx 1$ kendaraan

Dari hasil perhitungan diatas dapat disimpulkan bahwa untuk mobil pribadi membutuhkan jumlah booth sebanyak 1 booth dan dengan panjang antrian sebanyak 1 kendaraan.

\section{K. Penentuan desain Ramp}

Dalam menentukan desain ramp naik dan keluar menuju lahan Gedung Park and Ride ada beberapa aspek yang harus 


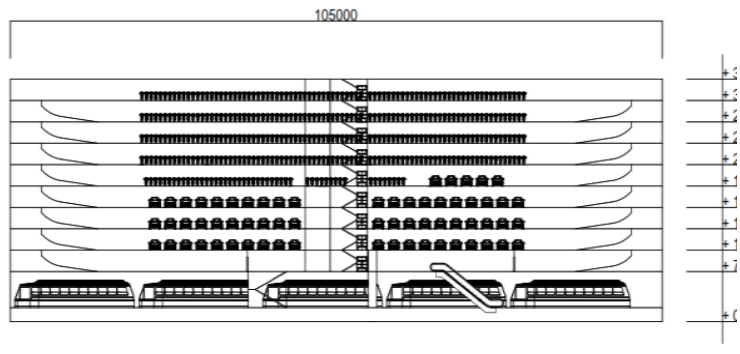

Đoronganneunungat

Gambar 8. Potongan Memanjang A-A.

diperhatikan dikarenakan lokasi park and ride berada di atas stasiun dimana menurut Peraturan Menteri Tahun 2012 tentang Peryaratan Teknis Jalur Kereta Api tinggi ruang bebas untuk kereta listrik menggunakan batas 4 yaitu setinggi 6,2 meter [3]. Jadi tinggi ramp yang akan digunakan pada perencanaan ini setinggi 7 meter.

Kemiringan desain ramp yang digunakan menurut Direktorat Jenderal Perhubungan Darat besarnya tanjakan maksimum pada ramp naik gedung parkir adalah $15 \%$ [4]. Maka dalam perencaan desain ramp naik ini dengan ketinggian $7 \mathrm{~m}$ dan dengan kemitingan sekitar 14,89\% maka dalam perencanaan ini menggunakan panjang horizontal sepanjang 47 meter dan panjang kemiringan tanjakan ramp sebesar 47,5 meter.

\section{Penentuan Pola Parkir}

Pola parkir mobil pribadi menggunakan pola parkir 1 sisi membentuk sudut $90^{\circ}$. Pola parkir untuk sepeda motor menggunakan pola parkir pulau membentuk sudut $90^{\circ}$.

\section{Lebar Gang}

Lebar gang parkir mobil digunakan sebesar 11 meter untuk lantai 1, 2, dan 3 sedangkan untuk lantai 4 menggunakan lebar gang sebesar 11,2 meter.

Lebar gang untuk area parkir motor digunakan sebesar 2 meter unutk lantai 4 dan 1,5 meter untuk lantai 5,6,7, dan 8 .

\section{N. Layout Parkir}

Dapat dilihat pada Gambar 4-9.

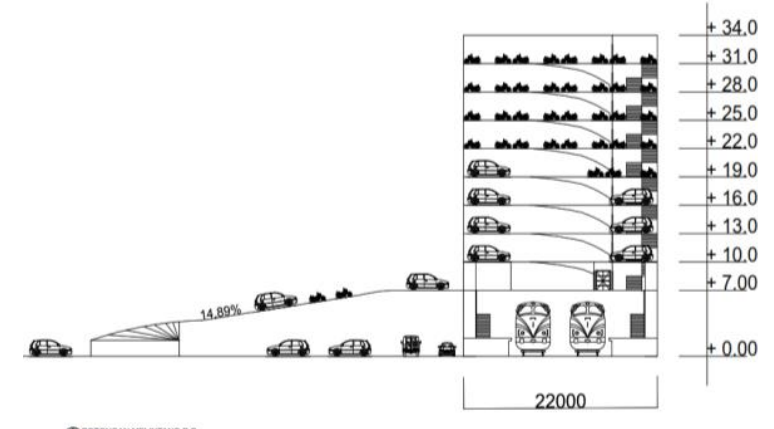

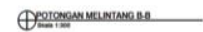

Gambar 9. Potongan Melintang B-B.

\section{KESIMPULAN}

1. Dari hasil analisis yang sudah dilakukan didapatkan probabilitas orang yang akan menggunakan park and ride di Stasiun Bojong Gede, Kabupaten Bogor sebagai berikut:

Pengendara Sepeda Motor $\quad=74 \%$

Pengendara Mobil $\quad=4 \%$

2. Dari hasil perhitungan dengan metode regresi linear sederhana, didapatkan demand pengguna park and ride untuk umur 5 tahun rencana (2024) sebesar 3.454 sepeda motor dan 192 untuk mobil pribadi

3. Setelah memalkukan perhitungan dan didapatkan jumlah demand park and ride yang paling maksimal, direncanakan desain gedung parkir sesuai aturan dan literatur yang ada

4. Dalam perencanaan Gedung Park and Ride yang sudah direncanakan didapatkan jumlah parkit yang tersedia dalam perencanaan layout ini ada sebanyak 3.479 untuk sepeda motor sedangkan untuk mobil sebanyak 193 ruang parkir.

\section{DAFTAR PUSTAKA}

[1] Badan Pusat Statistik, "Jumlah Penduduk Jawa Barat," 2019.

[2] S. Alfarizi, W. Herijanto, and C. Buana, "Perencanaan Gedung Park and Ride pada Terminal Bratang Surabaya," J. Tek. ITS, vol. 2, 2019.

[3] Menteri Perhubungan Republik Indonesia, "Peraturan Menteri Perhubungan Republik Indonesia No. 60. (2012). Dalam Persyaratan Teknis Jalur Kereta Api,” 2012.

[4] Direktorat Jenderal Perhubungan Darat, "Pedoman Teknis Penyelenggaraan Fasilitas Parkir," 1996. 